\title{
Modulation of nitric oxide synthases by oxyLDL: role in vascular inflammation
}

\section{and atherosclerosis development}

Micaela Gliozzi ${ }^{1}$, Miriam Scicchitano ${ }^{1}$, Francesca Bosco ${ }^{1}$, Vincenzo Musolino ${ }^{1}$, Cristina Carresi ${ }^{1}$,

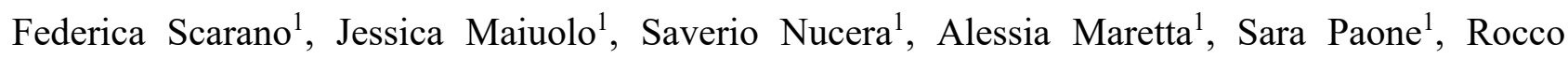
Mollace $^{2}$, Stefano Ruga ${ }^{1}$, Maria Caterina Zito ${ }^{1}$, Roberta Macrì ${ }^{1}$, Francesca Oppedisano ${ }^{1}$, Ernesto Palma $^{1}$, Carolina Muscoli ${ }^{1,3}$ and Vincenzo Mollace ${ }^{1,3 *}$

${ }^{1}$ Institute of Research for Food Safety \& Health IRC-FSH, University Magna Graecia, Catanzaro, Italy. ${ }^{2}$ Department of Medicine, Chair of Cardiology, University of Rome Tor Vergata,

${ }^{3}$ IRCCS San Raffaele Pisana, Roma, Italy.

*Corresponding author: Prof. Vincenzo Mollace, Institute of Research for Food Safety \& Health IRC-FSH, University Magna Graecia, Catanzaro, Italy. Tel.0039-09613694128, Fax 0039-09613695737.e-mail: mollace@libero.it 


\begin{abstract}
The release of nanomolar concentrations of nitric oxide (NO) by endothelial cells (EC), via activation of constitutive NO synthase (eNOS), represents the pre-requisite for the vaso-protective role of vascular endothelium. On the other hand, exaggerated release of NO as a consequence of activation of inducible NO synthase (iNOS), leads to endothelial dysfunction and, at the late stages, to the development of atherothrombosis. Oxidyzed LDLs (OxyLDL) represent the major candidate to trigger biomolecular processes accompanying endothelial dysfunction and vascular inflammation leading to atherosclerosis development though the pathophysiological mechanism still remains to be elucidated.

Here, we summarize recent evidence suggesting that oxyLDL produce significant impairment in the balance in the eNOS/iNOS machinery, downregulating eNOS via HMGB1-TLR4-Caveolin-1 pathway. On the other hand, a sustained activation of the scavenger receptor LOX-1 leads to NFkB activation which, in turn, increases iNOS, leading to EC oxidative stress. Finally, these events are associated to reduced protective autophagic response and accelerated apoptotic EC death which activates atherosclerotic development.

Taken togheter, these informations shed new light into the pathophysiological mechanisms of oxyLDL-related impairment of EC functionality and open new perspective in atherothrombosis prevention.
\end{abstract}

Key words: oxidized LDL,cNOS, iNOS, endothelial dysfunction. 


\section{Introduction}

Endothelial cells (EC) are the major component of the innermost layer of mammal blood vessels thereby representing a natural barrier which functionally serves to maintain separate the bloodstream from extra-vascular tissues. As a consequence, the integrity of vascular endothelium represents a key pre-requisite for regulating regional blood flow and many other mechanisms modulating vascular responses [1,2] including the inhibition of atherothrombotic disease development.

Among pathophysiological factors which have been identified to generate endothelial dysfunction, overproduction of oxidized low-density lipoproteins (oxyLDL) appears to play a crucial role in the development of atherosclerosis. Indeed, evidence has been accumulated demonstrating that oxyLDL produce pathophysiological effects, characterized by release of proinflammatory cytokines, overexpression of cell adhesion molecules, monocyte chemotactic protein-1, smooth muscle cells (SMC) growth factors, and impairment of endothelium-dependent vasorelaxation $[3,4]$. In addition, EC dysfunction due to overproduction of oxyLDL leads to imbalanced activation of constitutive (eNOS) thereby highlighting inducible (iNOS) isoform of nitric oxide (NO) synthase which, in turn, enhances inflammatory processes within vascular wall and contributes to atherosclerosis progression $[5,6,7]$.

The present review will summarize some recent advances in the bio-molecular mechanisms involved in the imbalanced modulation of NO biosynthesis and release, leading to EC dysfunction. In addition, the effect of oxyLDL-dependent impairment of NO-related pathway on proinflammatory mechanisms in the development of atherosclerosis will be focused.

\section{Mechanisms of NOS regulation}

The generation of NO represents the product of oxidation of the terminal guanidino nitrogen of L-arginine catalyzed by NOS through a highly regulated process. The three major isoforms of NOS have been distinguished on the basis of several parameters; in particular, amino acid sequences 
(only 50-60\% identity), tissue and cellular localization, and different regulation mechanisms have been considered for the classification. The calcium/calmodulin dependent NOS isoforms are expressed constitutively (cNOS) in endothelial cells (eNOS) and brain tissue (astrocytes and neurons in paarticular; nNOS), respectively $[8,9,10]$. The third NOS isoform is represented by the cytokine-inducible and calcium/calmodulin-independent form named (iNOS) $[8,9,11,12]$.

The distinct properties of each NOS isoform, such as the features of activation and the tissue localization, define both physiological or pathophysiological effects[13]. For example, the release of NO from cNOS occurs transiently, at nanomolar concentrations and cNOS-derived NO regulates organ blood flow distribution in the cardiovascular and renal system. In particular, at vascular level, it inhibits platelet aggregation, platelet and leukocyte adhesion and smooth muscle cell proliferation, whereas it promotes diuresis and natriuresis within the kidney $[8,9,14]$. In addition, it is involved in neurotransmission $[15,16]$. These effects are mainly due to the binding of $\mathrm{NO}$ to $\mathrm{Fe}^{2+}$ in the heme prosthetic group of soluble guanylate cyclase, responsible for the conversion of GTP to cyclic GMP $[8,9]$.

On the other hand, iNOS is overexpressed in response to different inflammatory stimuli, such as endogenous cytokines and bacterial lipopolysaccharide endotoxin (LPS) and causes a delayed but persistent synthesis of a large amount of NO $[8,9,12]$.

The cross-modulation of eNOS and iNOS actions in cardiovascular system represents a crucial event, aimed to ensure the right equilibrium between the constitutive, anti-atherogenic release of pulsed NO at nanomolar concentrations and the suppression of its inducible release at micromolar concentrations [17]. Thus, the maintenance of this balance reduces the potential dangerous effect of NO overproduction, which, after the reaction with superoxide anions, can trigger peroxidative processes [18].

It has been demonstrated that in different tissues expressing both cNOS and iNOS, as well as in cells expressing only inducible iNOS, both NO and NO donors can influence the production of either isoforms of these enzymes [19,5]. In particular, under basal conditions, cNOS-derived NO 
causes the inhibition of iNOS expression, suppressing NF-kB signalling [20,21]. On the other hand, extracellular stimuli, such as bacterial endotoxin and endogenous inflammatory cytokine, are able to induce NF-kB, thus triggering iNOS expression [22,23].

The NO-related inhibition of NF-kB is characterized by different mechanisms, which are not affecting the activation and translocation of NF-kB and are characterized by the interference of the interaction between NO and DNA. In particular, NO is able to modify the binding process of NF$\mathrm{kB}$ to its promoter response element [24,25], and it has been shown to also inhibit NF-kB/DNA binding through S-nitrosylation of the Cys 62 residue of p50 subunit [26].

In addition, NO interacts with NF-kB by stabilizing its endogenous inhibitor IkB [1]. Indeed, both $\mathrm{NO}$ and NO donors are able to prevent IkB degradation and its dissociation from NF-kB and to increase IkB mRNA expression without modulating mRNA expression of NF-kB (p65 and p50 subunits) [27]. As a consequence, after activation of iNOS by extracellular inducers of NF-kB, the early inhibitory effect of NO is replaced by its overproduction, which represent the main cause of peroxynitrite formation [28]. Peroxynitrite, in turn, probably via nitration of IKK, favours the shift of NF-kB in its active state, thus permitting iNOS activation [1].

\section{The effect of oxyLDL in the modulation of NOS isoforms}

Clear evidence suggests that oxyLDL produce early endothelial dysfunction. Indeed, the occurrence of high concentrations of circulating oxyLDL, as found in hyperlipemic patients as well as in subjects undergoing metabolic syndrome, have been associated to an altered reactive vasodilatation which represents the early stage of endothelial dysfunction [29]. The mechanism underlying oxyLDL-related endothelial dysfunction and inflammation of vascular tissues is still unclear. However, the relationship among the internalization of lipoproteins, the modulation of EC mediators, such as NO, and the activation of transcription factors, such as NF-kB, appears to have a relevant role in the development of atherosclerosis, though the mechanism is to be better clarified. In particular, it has been hypothesized that oxyLDL may suppress constitutive NO release via direct 
or indirect inhibition of eNOS, thereby leading to exaggerated activation of iNOS and subsequent toxic effect due to the reaction of NO with superoxide anions, generating peroxynitrite, which is responsible to EC damage [30]. In this context, a crucial role is played by the activity of the caveolae/NO coupled system.

Caveolae, 50-100 nm vesicular invaginations of the cell plasma membrane, represents the site of the important mechanisms occurring at the plasma membrane, such as vesicular trafficking and signal transduction [31]. The scaffolding protein Caveolin-1 is the main structural and signalling component of caveolae in different cells, including EC, which can interact with several molecules, thereby promoting important signalling functions [32].

eNOS is mostly targeted to caveolae in the plasma membrane of EC through interaction with caveolin-1 [32]. In particular, the binding of caveolin-1 to eNOS is a negative regulator of eNOS activity, and hypercholesterolemia-induced decrease of NO production is probably due to enhanced interaction of caveolin-1 with eNOS $[33,34]$, suggesting its involvement in endothelial dysfunction. The regulatory role of caveolae in endocytosis and transcytosis processes in EC is mainly influenced by its carrier function aimed to mediate the uptake and transcytosis of oxyLDL. This is confirmed by the action of two inhibitors, filipin and nocodazole, which counteracted oxyLDL uptake and transcytosis attenuating the crosstalk between oxyLDL and caveolae across the endothelial cell membrane [35].

OxyLDL have been also shown to upregulate caveolin-1 in a time-dependent manner, thus promoting the translocation of NF- $\mathrm{KB}$ and regulating the transcription of iNOS and LOX-1 [35]. In this scenario, caveolin-1 might promote oxyLDL uptake by EC and NF- $\kappa \mathrm{B}$ might be involved in this pathway.

The activity of Caveolin-1 is regulated by TRL4. In particular, evidence exists that Caveolin-1 Tyr14 phosphorylation is a crucial step in TLR4 signalling and, consequently, it mediates the inflammatory response in EC [36]. In particular, TLR4-mediated recruitment of the adaptor protein MyD88 induces the phosphorylation and the degradation of $\mathrm{IkB}$, favouring an early activation and 
translocation of NF- $\mathrm{KB}$ into the nucleus and, finally, cell death.

It has been hypothesized that high mobility group box 1 protein (HMGB1) may play a crucial role in the OxyLDL-induced development of atherosclerosis [37]. Furthermore, on the basis of the studies on HMGB1, it has been suggested a potential role for oxy-LDL-mediated TLR4/Caveolin-1 expression in EC, which represents a negative modulator of eNOS activity and induces high permeability in EC layer [38].

Summarizing, oxyLDL impair the balance between constitutive eNOS and inflammatory inducible iNOS in EC. This occurs via direct modulation of caveolin-1 (probably via HMGB-1 and subsequent TLR4 signalling), which promotes the translocation of NF-kB into the nucleus. This inhibits protective mechanisms such as eNOS function and protective autophagy leading, at the end stage, to EC apoptosis and subsequent endothelial dysfunction (Figure 1).

\section{Role of LOX-1 scavenger receptor in iNOS activation}

Evidence exists that vascular inflammation is mediated by several mechanisms depending on the overexpression of the lectin-like oxydized LDL (LOX-1), a scavenger receptor which selectively internalizes oxyLDL in EC [39]. LOX-1 is highly modulated by stimuli which have been shown to be involved in the development and progression of atherosclerosis, such as cytokines, mechanical forces and angiotensin II action, oxidative stress and directly by the occurrence of LDL oxidation $[6,39,40]$.

Recent data suggest that the detrimental effect of oxyLDL is mediated by an overexpression of the scavenger receptor LOX-1 in EC, which also appears to play a pivotal role in attenuating protective autophagy against apoptosis. Indeed, silencing LOX-1 receptor via ShRNA showed to restore autophagy and protect against oxyLDL-induced apoptotic cell death, thus suggesting the essential role of LOX-1 in mediating oxyLDL-dependent impairment of autophagy (Figure 1) [41].

Similar results have recently been found also in animal models of atherosclerotic disorders in 
carotid arteries; indeed, it has been demonstrated that oxidized LDL uptake through LOX-1 contributes to induce endothelial dysfunction observed in the early stages of this pathology $[38,42]$.

In particular, an increased production of reactive oxygen species (ROS), such as superoxide anions $\left(\mathrm{O}_{2}^{-}\right)$, occurs directly via LOX-1-induced NADPH oxidase activation $[43,44]$. In this context, ROS overproduction and the subsequent LOX-1 activation seems to impair PI-3-kinase/Akt pathway, causing an early attenuation of constitutive eNOS activity through inhibition of its phosphorylation/activation $[44,45]$.

The central role of eNOS dysfunction in the onset of atherosclerosis has been further confirmed by in vitro discoveries showing that in EC, oxyLDL elicited a time-dependent decrease in serine 1179 phosphorylation of eNOS, causing its inactivation and, at the same time, the impairment of physiological NO-mediated suppression of iNOS gene expression [46,21]. As a consequence, NO production by iNOS causes the generation of high levels of peroxynitrite, which has been correlated with EC death via apoptosis, as demonstrated by the enhancement of caspase-3 expression $[47,48]$.

The involvement of oxidative stress triggered by the interaction oxyLDL/LOX-1 was confirmed by detecting the effect of $\mathrm{N}$-acetylcysteine (NAC), a thiol-containing radical scavenger and glutathione precursor, able to counteract EC mortality induced by the oxidative damage [49]. Moreover, a similar effect was observed after recovering physiological NO levels, an effect achieved by treating BAEC with the NO donor S-nitroso-N-acetylpenicillamine (SNAP) [41].

This direct correlation between LOX-1 activation and free radical-induced apoptosis of EC has been also proven by using pterostilbene, a naturally occurring analogue of antioxidant resveratrol, which has been shown to inhibit oxyLDL-induced apoptosis of human EC through the downregulation of LOX-1 expression and the suppression of intracellular oxidative stress [50]. 


\section{The role of LOX-1/iNOS activation in the crosstalk between apoptosis and autophagy} of EC.

In the few last years, it has been hypothesized a more complex mechanism responsible for EC death via apoptosis. In particular, Lu et al showed that LOX-1 activation by L5, an electronegative component of LDL abundant in dyslipidemic but not in normolipidemic human plasma, selectively inhibited Bcl-xL and anti-apoptotic Bcl-2 expression and Akt and eNOS phosphorylation; moreover, LOX-1 activation induced an enhancement of proapototic Bax and Bad expression. Finally, L5 had been shown to cause the activation of caspase- 3 and mitochondrial release of cytochrome c, thus further favouring apoptosis $[47,51,52]$.

Bcl-2 protein family is divided into two different subgroups based on the presence of their Bcl-2 homology (BH) domain(s): anti-apoptotic proteins, such as Bcl-2 and Bcl-xL, and pro-apoptotic proteins, such as Bad and Bax. Bcl-2 family proteins regulate autophagy, which is also considered as a cellular defensive mechanism able to eliminate ROS induced damaged proteins $[53,54]$.

Beclin 1 is an important effector of autophagy, belonging to Bcl-2 family proteins which binds to a hydrophobic groove in $\mathrm{Bcl}-2 / \mathrm{Bcl}-\mathrm{xL}$ similarly to pro-apoptotic proteins of $\mathrm{Bcl}-2$ family. The formation of this complex, in turn, impairs autophagy and its inhibitory effect can be suppressed by the dissociation of Beclin 1 mediated by pro-apoptotic proteins $[55,56]$. This suggests that apoptosis and autophagy may be co-regulated in the same directions; as a consequence, in the presence of stimuli (i.e. LOX-1 activation by L5 or oxyLDL) able to downregulate $\mathrm{Bcl}-2 / \mathrm{Bcl}-\mathrm{xL}$ and to induce pro-apoptotic proteins $[57,58]$, it is conceivable that the switch between autophagy and apoptosis is regulated through alternative mechanisms.

In particular, it has been demonstrated that Beclin 1, being a direct caspase substrate, can lose its autophagy-inducing property after its cleavage; indeed, after the direct interaction of its C-terminal fragment with mitochondria, it causes the release of pro-apoptotic factors, thus promoting apoptosis [59].

In vitro experiments supported this theory. In particular, under starvation experimental settings 
able to activate autophagic response, a reduced expression of oxyLDL-induced Beclin 1 was observed being this effect also correlated to an increased expression of iNOS and caspase-3. This suggests that the oxidative stimulus was not able to restore physiologic NO levels early, favouring free radical overproduction and caspase-induced Beclin-1 cleavage; the result of these mechanisms triggered by oxyLDL was represented by a suppression of autophagy associated with an enhanced apoptosis $[41,60]$.

The balance between protective autophagy and apoptotic cell death by LOX-1 has also been further confirmed by the up-regulation of another marker of autophagy, LC3 II (microtubule associated protein 1A/1B-light chain 3 type II), an effect reverted after LOX-1 silencing, via LOX1 shRNA [60,61].

\section{Conclusion}

Taken together, data reported in this review article suggest that oxyLDL lead to direct and indirect impairment of constitutive release of NO highlighting overexpression of inducible iNOS. This effect, combined with overproduction of ROS, leads to endothelial cell dysfunction and subsequent development of atherosclerosis. The activation of LOX-1 receptor and subsequent activation of NFkB represents key events in this complex dysregulation of NOS isoforms, contributing to attenuation of protective autophagic response and an accelerated EC apoptotic death which is the end stage of endothelial dysfunction. These informations allow to better define the pathophysiology of imbalanced regulation of NOS isoforms which occurs at early stages of atherosclerotic process and represent a perspective for selective therapeutic interventions in cardiovascular disease prevention. 
Author Contributions: Vincenzo Mollace (VM) conceptualized and designed the manuscript; MG and Vincenzo Mollace (VM) wrote the manuscript; MS, FB, Vincenzo Musolino (VM), CC, FS, JM, SN, AM, SP, RM, SR, MCZ, RM, FO, EP, CM participate in drafting the article and revising it critically.

Funding: The work has been supported by the public resources from the Italian Ministry of Research.

Acknowledgments: This work has been supported by PON-MIUR 03PE000_78_1 and PONMIUR 03PE000_78_2.

Conflicts of Interest: The authors declare no conflicts of interest. 


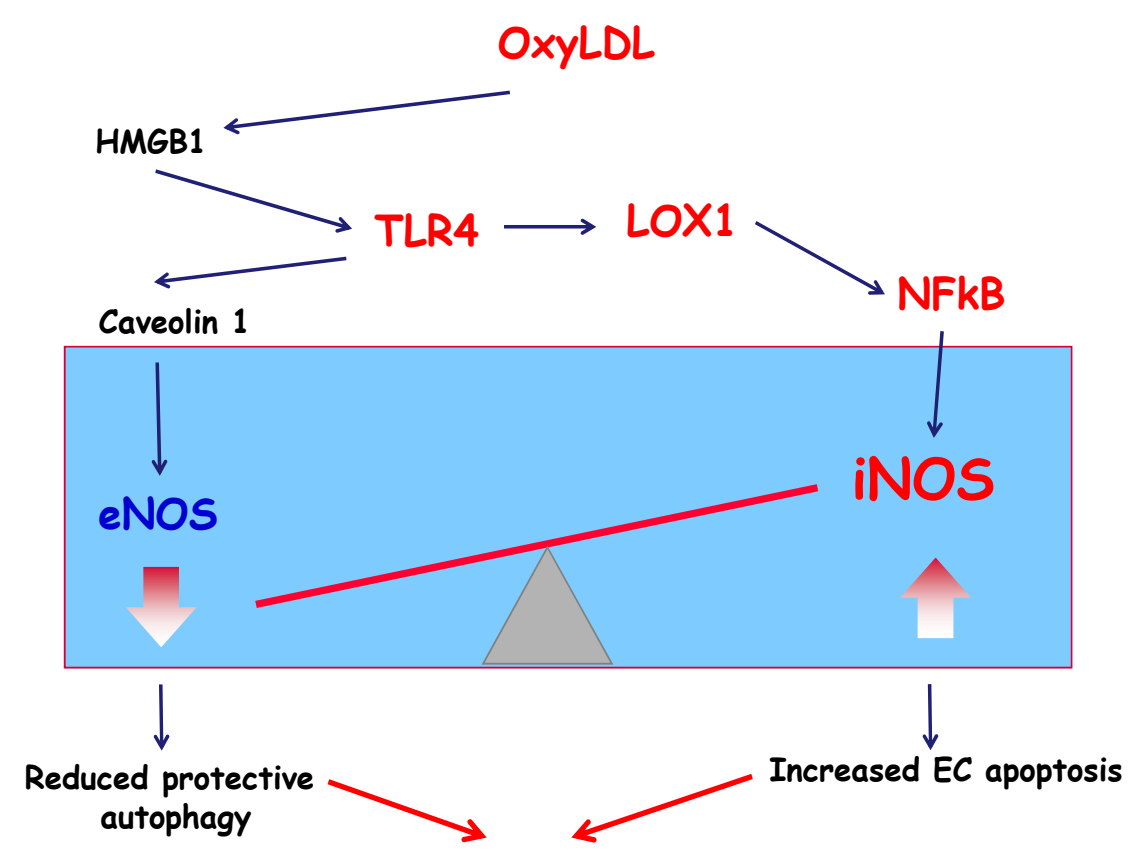

Endothelial Dysfunction

Figure 1

Proposed mechanism of oxy-LDL-related endothelial dysfunction via imbalanced regulation of eNOS/iNOS relationship. In particular, oxyLDL modulates HGMB1/TRL4/caveolin-1 signalling in eNOS/iNOS balance which impairs autophagic/apoptotic responses in vascular and non/vascular cells. 


\section{References}

1. Maiuolo, J.; Gliozzi, M.; Musolino, V.; Scicchitano, M.; Carresi, C.; Scarano, F.; Bosco, F.; Nucera, S.; Ruga, S.; Zito, M.C.; Mollace, R.; Palma, E.; Fini, M.; Muscoli, C.; Mollace, V. The "Frail" Brain Blood Barrier in Neurodegenerative Diseases: Role of Early Disruption of Endothelial Cell-to-Cell Connections. Int J Mol Sci 2018, 19, 2693, doi: 10.3390/ijms 19092693 .

2. Lanuti, P.; Rotta, G.; Almici, C.; Avvisati, G.; Budillon, A.; Doretto, P.; Malara, N.; Marini, M.; Neva, A.; Simeone, P.; Di Gennaro, E.; Leone, A.; Falda, A.; Tozzoli, R.; Gregorj, C.; Di Cerbo, M.; Trunzo, V.; Mollace, V.; Marchisio, M.; Miscia, S. Endothelial progenitor cells, defined by the simultaneous surface expression of VEGFR2 and CD133, are not detectable in healthy peripheral and cord blood. Cytometry A 2016, 89, 259-70, doi: 10.1002/cyto.a. 22730 .

3. Li, D.; Mehta, J.L. Antisense to LOX-1 inhibits oxidized LDL-mediated upregulation of monocyte chemoattractant protein-1 and monocyte adhesion to human coronary artery endothelial cells. Circulation 2000, 101, 2889-2895.

4. Szmitko, P.E.; Wang, C.H.; Weisel, R.D.; de Almeida, J.R.; Anderson, T.J.; Verma, S. New markers of inflammation and endothelial cell activation: part I. Circulation 2003, 108, $1917-$ 1923, doi:10.1161/01.CIR.0000089190.95415.9F.

5. Colasanti, M., Suzuki, H. The dual personality of NO. Trends Pharmacol Sci 2000, 21, 249252, doi:https://doi.org/10.1016/S0165-6147(00)01499-1.

6. Mehta, J.L.; Li, D. Identification, regulation and function of a novel lectin like oxidized lowdensity lipoprotein receptor. J Am Coll Cardiol 2002, 39, 1429-1435, doi:https://doi.org/10.1016/S0735-1097(02)01803-X.

7. Mollace, V.; Sacco, I.; Janda, E.; Malara, C.; Ventrice, D.; Colica, C.; Visalli, V.; Muscoli, S.; Ragusa, S.; Muscoli, C.; Rotiroti, D.; Romeo, F. Hypolipemic and hypoglycaemic activity of bergamot polyphenols: from animal models to human studies. Fitoterapia 2011,82, 309-16, doi:10.1016/j.fitote.2010.10.014. 
8. Moncada, S.; Palmer, R.M.; Higgs, E.A. Nitric oxide: physiology, pathophysiology, pharmacology. Pharmacol Rev 1991, 43, $109-142$.

9. Lamoke, F.; Mazzone, V.; Persichini, T.; Maraschi, A.; Harris, M.B.; Venema, C.; ,Marco Colasanti, M.; Gliozzi,M.; Muscoli, C.; Bartoli, M. and Mollace, V. Amyloid $\beta$ peptideinduced inhibition of endothelial nitric oxide production involves oxidative stress-mediated constitutive eNOS/HSP90 interaction and disruption of agonist-mediated Akt activation. J Neuroinflammation. 2015; 12-18: 84

10. Mollace, V.; Salvemini, D.; Anggård, E.; Vane, J. Cultured astrocytoma cells inhibit platelet aggregation by releasing a nitric oxide-like factor. Biochem Biophys Res Commun 1990, $172,564-9$.

11. Mollace, V.; Muscoli, C.; Rotiroti, D.; Nisticó, G. Spontaneous induction of nitric oxideand prostaglandin E2-release by hypoxic astroglial cells is modulated by interleukin 1 beta. Biochem Biophys Res Commun 1997, 238, 916-9, doi:10.1006/bbrc.1997.7155.

12. Salvemini, D.; Mollace, V.; Pistelli, A.; Anggård, E.; Vane, J. Cultured astrocytoma cells generate a nitric oxide-like factor from endogenous L-arginine and glyceryl trinitrate: effect of E. coli lipopolysaccharide. Br J Pharmacol 1992, 106, 931-6.

13. Mollace, V.; Rodino, P.; Massoud, R.; Rotiroti, D. Nistico G.Age-dependent changes of NO synthase activity in the rat brain. Biochem Biophys Res Commun 1995, 215,822-7.

14. Salvemini, D.; Currie, M.G.; Mollace, V. Nitric oxide-mediated cyclooxygenase activation. A key event in the antiplatelet effects of nitrovasodilators. J Clin Invest 1996, 97,2562-8, doi:10.1172/JCI118704.

15. Bredt, D.S.; Snyder, S.H. Nitric oxide: a physiologic messenger molecule. Annu Rev Biochem 1994, 63, 175-195, doi:10.1146/annurev.bi.63.070194.001135.

16. Nathan, C. Nitric oxide as a secretory product of mammalian cells. FASEB J 1992, 6, 30513064.

17. Colasanti, M.; Cavalieri, E.; Persichini, T.; Mollace, V.; Mariotto, S.; Suzuki, H.; Lauro, GM. Bacterial lipopolysaccharide plus interferon-gamma elicit a very fast inhibition of a 
$\mathrm{Ca} 2+-$ dependent nitric-oxide synthase activity in human astrocytoma cells. J Biol Chem $1997,272,7582-5$.

18. Mollace, R.; Gliozzi, M.; Tavernese, AM.; Musolino, V.; Carresi, C.; Scicchitano, M.; Palma, E.; Nucera, S.; Bosco, F.; Scarano, F.; Oppedisano, F.; Maretta, A.; Maiuolo, J.; Muscoli, S.; Gratteri, S.; Romeo, F.; Mollace, V. Bergamot Polyphenolic Fraction supplementation improves metabolic balance, endothelial function and maximal oxygen uptake in athletes. Journal of Sports Medicine and Therapy 2018, doi:10.29328/journal.jsmt.1001027.

19. Colasanti, M.; Persichini, T. Nitric oxide: an inhibitor of NF-KB/Rel system in glial cells. Brain Res Bull 2000, 52, 155-161, doi:10.1016/S0361-9230(00)00262-8.

20. Togashi, H.; Sasaki, M.; Frohman, E.; Taira, E.; Ratan, R.R.; Dawson, T.M.; Dawson, V.L. Neuronal (type I) nitric oxide synthase regulates nuclear factor- B activity and immunologic (type II) nitric oxide synthase expression. Proc Natl Acad Sci USA 1997, 94, 2676 -2680.

21. Janda, E.; Visalli, V.; Colica, C.; Aprigliano, S.; Musolino, V.; Vadalà, N.; Muscoli, C.; Sacco, I.; Iannone, M.; Rotiroti, D., Spedding, M.; Mollace, V. The protective effect of tianeptine on Gp120-induced apoptosis in astroglial cells: role of GS and NOS, and NF-kB suppression. Br J Pharmacol 2011, 164, 1590-1599, doi:10.1111/j.1476-5381.2010.01172.x.

22. Bonaiuto, C.; McDonald, P.P.; Rossi, F.; Cassatella, M.A. Activation of nuclear factor- B by amyloid peptides and interferon-gamma in murine microglia. J Neuroimmunol 1997, 77, $51-56$.

23. Massa, P.T.; Wu, C. Increased inducible activation of NF- B and responsive genes in astrocytes deficient in the protein tyrosine phosphatase SHP-1. J Interferon Cytokine Res 1998, 18, 499 -507.

24. DelaTorre, A.; Schroeder, R.A.; Bartlett, S.T.; Kuo, P.C. Differential effects of nitric oxidemediated S-nitrosylation on p50 and c-jun DNA binding. Surgery 1998, 124, 137-141, discussion 141-132. 
25. Matthews, J.R.; Botting, C.H.; Panico, M.; Morris, H.R.; Hay, R.T. Inhibition of NF- kB DNA binding by nitric oxide. Nucleic Acids Res 1996, 24, 2236 - 2242.

26. Mollace, V.; Muscoli, C.; Masini, E.; Cuzzocrea, S.; Salvemini, D. Modulation of prostaglandin biosynthesis by nitric oxide and nitric oxide donors. Pharmacol Rev 2005, 57, 217-52, doi:10.1124/pr.57.2.1.

27. Peng, H.B.; Libby, P.; Liao, J.K. Induction and stabilization of I Bby nitric oxide mediates inhibition of NF- B. J Bioll Chem 1995, 270, 14214 - 14219.

28. Aquaro, S.; Muscoli, C.; Ranazzi, A.; Pollicita, M.; Granato, T.; Masuelli, L.; Modesti, A.; Perno, CF.; Mollace, V. The contribution of peroxynitrite generation in HIV replication in human primary macrophages. Retrovirology 2007, 4, 76, doi:10.1186/1471-2202-10-51.

29. Gliozzi, M.; Carresi, C.; Musolino, V.; Palma, E.; Muscoli, C.; Vitale, C.; Gratteri, S.; Muscianisi, G.; Janda, E.; Muscoli, S.; Romeo, F.; Ragusa, S.; Mollace, R.; Walker, R.; Ehrlich, J.; Mollace, V. The Effect of Bergamot-Derived Polyphenolic Fraction on LDL Small Dense articles and Non Alcoholic Fatty Liver Disease in Patients with Metabolic Syndrome. Advances in Biological Chemestry 2014, 4, 129-137, doi: $10.4236 / \mathrm{abc} .2014 .42017$

30. Tassone, E.J.; Perticone, M.; Sciacqua, A.; Mafrici, S.F.; Settino, C.; Malara, N.; Mollace, V.; Sesti, G.; Perticone, F. Low dose of acetylsalicylic acid and oxidative stress-mediated endothelial dysfunction in diabetes: a short-term evaluation. Acta Diabetol 2015, 52, 249 256, doi:10.1007/s00592-014-0629-4.

31. Frank, P.G.; Galbiati, F.; Volonte, D.; Razani, B.; Cohen, D.E.; Marcel, Y.L.; Lisanti, M.P.; Influence of caveolin-1 on cellular cholesterol efflux mediated by high-density lipoproteins. Am J Physiol Cell Physiol 2001, 280, C1204-14, doi:10.1152/ajpcell.2001.280.5.C1204.

32. Feron, O.; Belhassen, L.; Kobzik, L.; Smith, T.W.; Kelly, R.A.; Michel, T. Endothelial nitric oxide synthase targeting to caveolae. Specific interactions with caveolin isoforms in cardiac myocytes and endothelial cells. J Biol Chem 1996, 271, 22810-4, doi:10.1074/jbc.271.37.22810. 
33. Feron, O. Endothelial nitric oxide synthase expression and its functionality. Curr Opin Clin Nutr Metab Care 1999, 2, 291-6.

34. Mollace, V.; Gliozzi, M.; Carresi, C.; Musolino, V.; Oppedisano, F. Re-assessing the mechanism of action of n-3 PUFAs. Int $\mathrm{J}$ Cardiol. 2013, 170, S8-11, doi: 10.1016/j.ijcard.2013.06.038.

35. Sun S.W.; Zu, X.Y.; Tuo, Q.H.; Chen, L.X.; Lei, X.Y.; Li, K.; Tang, C.K.; Liao, D.F. Caveolae and caveolin-1 mediate endocytosis and transcytosis of oxidized low density lipoprotein in endothelial cells. Acta Pharmacol Sin 2010, 31, 1336-1342, doi:10.1038/aps.2010.87.

36. Jiao, H.; Zhang, Y.; Yan, Z.; Wang, Z.G.; Liu, G.; Minshall, R.D.; Malik, A.B.; Hu G. Caveolin-1 Tyr14 phosphorylation induces interaction with TLR4 in endothelial cells and mediates MyD88-dependent signalingand sepsis-induced lung inflammation. J Immunol 2013, 191, doi:10.4049/jimmunol.1300873.

37. Qin, Z.; Zhaowei, Z.; Xinqun, H.; Chang, S. HMGB1: a critical mediator for oxidized-low density lipoproteins induced atherosclerosis. Int J Cardiol 2016, 202, 956-957, doi:https://doi.org/10.1016/j.ijcard.2015.08.203.

38. Sawamura, T.; Kume, N.; Aoyama, T.; Moriwaki, H.; Hoshikawa, H.; Aiba, Y.; Tanaka, T.; Miwa, S.; Katsura, Y.; Kita, T.; Masaki,T. An endothelial receptor for oxidized low density lipoprotein. Nature 1997, 386 73-77, doi:10.1038/386073a0.

39. Kume, N.; Kita, T. Lectin-like oxidized low-density lipoprotein receptor-1 (LOX-1) in atherogenesis. Trends Cardiovasc Med 2001, 11, 22-25, doi: https://doi.org/10.1016/j.cardiores.2005.09.006.

40. Mollace, V.; Ragusa, S.; Sacco, I.; Muscoli, C.; Sculco, F.; Visalli, V.; Palma, E.; Muscoli, S.; Mondello, L.; Dugo, P.; Rotiroti, D.; Romeo, F. The protective effect of bergamot oil extract on lecitine-like oxyLDL receptor-1 expression in balloon injury-related neointima formation. J Cardiovasc Pharmacol Ther 2008, 3, 120129, doi:10.1177/1074248407313821. 
41. Mollace, V.; Gliozzi, M.; Musolino, V.; Carresi, C.; Muscoli, S.; Mollace, R.; Tavernese, A,M.; Gratteri, S.; Palma, E.; Morabito, C.; Vitale, C.; Muscoli, C.; Fini, M.; Romeo, F. Oxidized LDL attenuates protective autophagy and induces apoptotic cell death of endothelial cells: Role of oxidative stress and LOX-1 receptor expression. Int J Cardiol $2015,184,152-158$.

42. Muscoli, C.; Sacco, I.; Alecce, W.; Palma, E.; Nisticò, R.; Costa, N.; Clementi, F.; Rotiroti, D.; Romeo, F.; Salvemini, D.; Mehta, J.L.; Mollace, V. The protective effect of superoxide dismutase mimetic M40401 on balloon injury-related neointima formation: role of the lectin-like oxidized low-density lipoprotein receptor-1. J Pharmacol Exp Ther 2004, 311, 44-50, doi:10.1124/jpet.104.068205.

43. Liao, L.; Aw, T.Y.; Kvietys, P.R.; Granger, D.N. Oxidized LDL-induced microvascular dysfunction. Dependence on oxidation procedure. Arterioscler Thromb Vasc Biol 1995, 15, 2305-2311.

44. Ou, H.C.; Song, T.Y.; Yeh, Y.C.; Huang, C.Y.; Yang, S.F.; Chiu, T.H.; Tsai, K.L.; Chen, K.L.; Wu, Y.J.; Tsai, C.S.; Chang, L.Y.; Kuo, W.W.; Lee, S.D. EGCG protects against oxidized LDL induced endothelial dysfunction by inhibiting LOX-1-mediated signalling. J Appl Physiol 2010, 108, 1745-1756, doi:10.1152/japplphysiol.00879.2009.

45. Kume, N.; Kita, T. Apoptosis of vascular cells by oxidized LDL: involvement of caspases and LOX-1 and its implication in atherosclerotic plaque rupture. Circ Res 2004, 94, 269270, doi:10.1161/01.RES.0000119804.92239.97.

46. Salvemini, D.; Kim, S.F.; Mollace, V. Reciprocal regulation of the nitric oxide and cyclooxygenase pathway in pathophysiology: relevance and clinical implications. Am J Physiol Regul Integr Comp Physiol 2013, 304, R473-R487, doi:10.1152/ajpregu.00355.2012.

47. Zhang, L.; Zhou, G.Z.; Song, W.; Tan, X.R.; Guo, Y.Q.; Zhou, B.; Jing, H.; S.J. Zhao, S.J.; Chen, L.K. Pterostilbene protects vascular endothelial cells against oxidized low-density lipoprotein-induced apoptosis in vitro and in vivo. Apoptosis 2012, 17, 25-36, doi:10.1007/s10495-011-0653-6. 
48. Tang, D.; Lu, J.; Walterscheid, J.P.; Chen, H.H.; Engler, D.A.; Sawamura, T.; Chang, P.Y.; Safi, H.J.; Yang, C.Y.; Chen, C.H. Electronegative LDL circulating in smokers impairs endothelial progenitor cell differentiation by inhibiting Akt phosphorylation via LOX-1. J Lipid Res 2008, 49, 33-47, doi: 10.1194/jlr.M700305-JLR200.

49. Janda, E.; Lascala, A.; Carresi, C., Parafati, M.; Aprigliano, S.; Russo, V.; Savoia, C.; Ziviani, E.; Musolino, V.; Morani, F.; Isidoro, C.; Mollace, V. Parkinsonian toxin-induced oxidative stress inhibits basal autophagy in astrocytes via NQO2/quinone oxidoreductase 2: Implications for neuroprotection. Autophagy 2015, 11, 1063-80, doi: 10.1080/15548627.2015.1058683.

50. Gliozzi, M.; Walker, R.; Muscoli, S.; Vitale, C.; Gratteri, S.; Carresi, C.; Musolino, V.; Russo, V.; Janda, E.; Ragusa, S.; Aloe, A.; Palma, E., Muscoli, C., Romeo, F., Mollace, V. Bergamot polyphenolic fraction enhances rosuvastatin-induced effect on LDL-cholesterol, LOX-1 expression and protein kinase B phosphorylation in patients with hyperlipidemia. Int J Cardiol 2013, 170,140-145, doi:10.1016/j.ijcard.2013.08.125.

51. Li, D.; Mehta, J.L. Intracellular signaling of LOX-1 in endothelial cell apoptosis. Circ Res 2009, 104, 566-568, doi:10.1161/CIRCRESAHA.109.194209.

52. Lu, J.; Yang, J.H.; Burns, A.R.; Chen, H.H.; Tang, D.; Walterscheid, J.P.; Suzuki, S.; Yang, C.Y.; Sawamura, T.; Chen, C.H. Chemical composition-oriented receptor selectivity of L5, a naturally occurring atherogenic low-density lipoprotein. Circ Res 2009, 104, 619-627, doi:10.1351/PAC-CON-10-12-07.

53. Luo, S.; Rubinsztein, D.C. Apoptosis blocks Beclin 1-dependent autophagosome synthesis: an effect rescued by Bcl-xL. Cell Death Differ 2010, 17, 268-277, doi: 10.1038/cdd.2009.121.

54. Carresi, C.; Musolino, V.; Gliozzi, M.; Maiuolo, J.; Mollace, R.; Nucera, S.; Maretta, A.; Sergi, D.; Muscoli, S.; Gratteri, S.; Palma, E.; Bosco, F.; Giancotta, C.; Muscoli, C.; Marino, F.; Aquila, I.; Torella, D.; Romeo, F.; Mollace, V. Anti-oxidant effect of bergamot polyphenolic fraction counteracts doxorubicin-induced cardiomyopathy: Role of autophagy and ckitposCD45negCD31neg cardiac stem cell activation. J Mol Cell Cardiol 2018, 119, 10-18, doi:10.1016/j.yjmcc.2018.04.007. 
55. Oberstein, A.; Jeffrey, P.D.; Shi, Y. Crystal structure of the Bcl-XL-Beclin 1 peptide complex: Beclin 1 is a novel BH3-only protein. J Biol Chem 2007, 282, 13123-13132, doi:10.1074/jbc.M700492200.

56. Maiuri, M.C.; Le Toumelin, G.; Criollo, A.; Rain, J.C.; Gautier, F.; Juin, P.; Tasmedir, E.; Pierron, G.; Troulinaki, K.; Tavernarakis, N.; Hickman, J.A.; Geneste, O.; Kroemer, G. Functional and physical interaction between Bcl-X(L) and a BH3-like domain in Beclin-1. EMBO J 2007, 26, 2527-2539, doi:10.1038/sj.emboj.7601689.

57. Rusiñol,A.E.; Thewke, D.; Liu, J.; Freeman, N.; Panini, S.R.; Sinensky, M.S. AKT/protein kinase B regulation of BCL family members during oxysterol-induced apoptosis. J Biol Chem 2004, 279, 1392-1399, doi:10.1074/jbc.M308619200.

58. Chen, W.L.; Qian, Y.; Meng, W.F.; Pang, J.Y.; Lin, Y.C.; Guan, Y.Y.; Chen, S.P.; Liu, J.; Pei, Z.; Wanga, G.L. A novel marine compound xyloketal B protects against oxidized LDL induced cell injury in vitro. Biochem Pharmacol 2009, 78, 941-950, doi: 10.1016/j.bcp.2009.05.029.

59. Amelio, I.; Melino, G.; Knight, R.A. Cell death pathology: cross-talk with autophagy and its clinical implications. Biochem Biophys Res Commun 2011, 414, 277-281, doi:https://doi.org/10.1016/j.bbrc.2011.09.080.

60. Parafati, M., Lascala, A.; Morittu, V.M,; Trimboli, F.; Rizzuto, A.; Brunelli, E.; Coscarelli, F.; Costa, N.; Britti, D.; Ehrlich, J.; Isidoro, C.; Mollace, V.; Janda, E.. Bergamot polyphenol fraction prevents nonalcoholic fatty liver disease via stimulation of lipophagy in cafeteria diet-induced rat model of metabolic syndrome. J Nutr Biochem 2015, 26, 938-48. doi:10.1016/j.jnutbio.2015.03.008.

61. Miracco, C.; Cevenini, G.; Franchi, A.; Luzi, P.; Cosci, E.; Mourmouras, V.; Monciatti, I.; Mannucci, S.; Biagioli, M.; Toscano, M.; Moretti, D.; Lio, R.; Massi, D. Beclin 1 and LC3 autophagic gene expression in cutaneous melanocytic lesions. Hum Pathol 2010, 41, 503512, doi:10.1016/j.humpath.2009.09.004. 